\title{
USO DE TICS EM CONJUNTO COM A METODOLOGIA DE APRENDIZAGEM BASEADA EM PROBLEMAS NO ENSINO DE ALGORITMOS: UM ESTUDO DE CASO APLICADO A UM CURSO TÉCNICO DO IFMG
}

\author{
USING ICT WITH PROBLEM BASED LEARNING TO THE ALGOTITHM LEARNING TEACHING: A USE CASE \\ APPLIED IN A TECHNICAL COURSE OF THE FEDERAL INSTITUTE OF MINAS GERAIS
}

\begin{abstract}
USO DE TICS EN CONEXIÓN CON LOS PROBLEMAS DE LA METODOLOGÍA DE APRENDIZAJE EN LA ENSEÑNANZA DE ALGORITMOS: UN ESTUDIO DE CASO APLICADO A UN CURSO TÉCNICO DEL IFMG
\end{abstract}

\author{
Bruno Ferreira \\ Doutor em ciência da computação pelo DCC-UFMG. Instituto Federal de Minas Gerais - Campus Formiga. \\ E-mail: bruno.ferreira@ifmg.edu.br. \\ Orcid: https://orcid.org/0000-0002-5942-3521
}

\author{
Edio da Costa Junior \\ Doutor em Geofísica Espacial pelo INPE, Instituto Federal de Minas Gerais - Campus Formiga. \\ E-mail: edio.junior@ifmg.edu.br. \\ Orcid: https://orcid.org/0000-0002-2432-2691
}

\author{
Wesley Gomes de Almeida \\ Doutor em Computação Aplicada pelo INPE, Instituto Federal de Minas Gerais - Campus São João \\ Evangelista. \\ E-mail: wesley.almeida@ifmg.edu.br. \\ Orcid: https://orcid.org/0000-0003-0372-930X
}

\begin{abstract}
RESUMO
A presente pesquisa teve como objetivo aplicar e analisar o uso de Tecnologia da Informação e Comunicação (TIC), em conjunto com a metodologia de aprendizagem baseada por problemas (ABP), no ensino de algoritmos em um curso Técnico de Informática do Instituto Federal de Minas Gerais (IFMG). $O$ trabalho foi desenvolvido por meio de experimentação de campo via projeto de ensino, o qual foi executado por dois anos com estudantes do ensino técnico. Foram realizadas análises acadêmicas dos estudantes participantes e não participantes do projeto e também uma avaliação por meio de um questionário para compreender a percepção dos estudantes perante as novas metodologias aplicadas. Contudo, foi possível constatar que os alunos participantes do projeto mostraram desempenho acadêmico superior, referente à disciplina de Introdução à Programação em relação aos alunos que não tiveram contato com a metodologia proposta. Os estudantes também demonstraram apreço pela metodologia do projeto indicando maior aprendizagem e motivação referente aos assuntos ligados às disciplinas de programação.
\end{abstract}

Palavras-chave: Aprendizagem baseado em problemas. TICs. Algoritmos. Ensino Técnico. 


\begin{abstract}
This research presents the usage analysis of Information and Communication Technology (ICTs) with Problems Based Learning methodology to the algorithm's teaching in a technical course at Federal Institute of Minas Gerais (IFMG). Work was developed through experimentation by an educational project, which was ran for two years with technical students. A behavior analysis of the participating and not participating students was carried out, in addition to an evaluation through a questionnaire in order to know the students' perception about the new applied methodology. However, it was possible to verify that the students participating in the project showed better performance, referring to the discipline of Programming in relation to students who did not have contact with the proposed methodology. The students also showed appreciation for the project's methodology, indicating greater learning and motivation during the subjects related to programming disciplines.
\end{abstract}

Keywords: Problems based learning. ITCs. Algorithms. Technical course.

\title{
RESUMEN
}

Esta investigación tuvo como objetivo aplicar y analizar el uso de la Tecnología de la Información y la Comunicación (TIC), junto con la metodología de aprendizaje basada en problemas (PBL), en la enseñanza de algoritmos en un curso de Informática en el Instituto Federal de Minas General (IFMG). El trabajo se desarrolló a través de la experimentación de campo a través de un proyecto de enseñanza, que se realizó durante dos años con estudiantes de educación técnica. Se llevaron a cabo análisis académicos de los estudiantes que participaron y no participaron en el proyecto, así como una evaluación utilizando un cuestionario para comprender la percepción de los estudiantes sobre las nuevas metodologías aplicadas. Sin embargo, fue posible verificar que los estudiantes que participaron en el proyecto mostraron un rendimiento académico superior, con respecto a la disciplina de Introducción a la programación en relación con los estudiantes que no tuvieron contacto con la metodología propuesta. Los estudiantes también mostraron aprecio por la metodología del proyecto, lo que indica un mayor aprendizaje y motivación con respecto a temas relacionados con las disciplinas de programación.

Palabras-clave: Aprendizaje basado en problemas. Las TIC. Algoritmos. Educación técnica.

\section{INTRODUÇÃO}

O termo algoritmo não é novo e foi sendo formulado desde o surgimento do sistema de notação numérico hindu-arábico e da escrita dos cálculos algébricos pelo árabe Al-Kharazmi, contudo, foi a partir de 1250 d. c. que o matemático e astrônomo John Halifax apresentou conceitos mais concretos. Hoje esses conceitos e sua lógica são as bases para a Ciência da Computação (FILHO, 2007, p. 33). Cormen et al. (2002, p. 22) e Manzano e Oliveira (1997) descrevem que um algoritmo é uma sequência finita de instruções bem definidas e não ambíguas. Cada uma dessas instruções deve ser executada num período de tempo específico e com uma quantidade de esforço limitada, visando um fim. Contudo, existem diversas variações dessa definição, mas para esse 
De acordo com Souza (2008, p.6), é importante para a escrita de algoritmos, um bom raciocínio lógico-dedutivo, ou seja, a lógica que precisa ser desenvolvida é aquela que "diga como as pessoas devem raciocinar" para escrever sequência de comandos que resolvam uma determinada tarefa com sucesso. A fim de reforçar essa ideia, Araújo (2007, p.33) afirma que a pessoa por trás de um algoritmo deve saber organizar a forma de pensar, o indivíduo deve tomar consciência dos elementos fundamentais à capacidade de argumentar e expor ideias. Talvez sejam essas características que tornam o ensino e a aprendizagem desse conteúdo difícil. Na mesma linha de pensamento, Setti (2009, p.11), explica que os maiores obstáculos epistemológicos à aprendizagem de algoritmos é justamente, a forma de pensar ou a forma de raciocinar sobre a solução de um determinado problema e, aponta que o domínio sobre os conceitos da Matemática Discreta e da Lógica Matemática (ensino das proposições lógicas) pode ser importante em conjunto com metodologias de ensino adequadas.

Esse grau de conhecimento matemático, a falta de apresentação da importância do uso de algoritmos em várias áreas da tecnológica e a dependência das disciplinas de introdução aos algoritmos em relação aos demais componentes curriculares dos cursos da área da Computação, tendem a serem as principais causas dos altos índices de reprovação dos alunos do ensino técnico e superior (SANTOS e COSTA, 2006; BARCELOS, TAROUCO e BERCHT, 2009). Para confirmar esse fato, Timmermann (2015, p. 14) apresenta uma pesquisa realizada pela Associação Brasileira das Empresas de Tecnologia da Informação e Comunicação (Brasscom), a qual apontava o assustador percentual de $82 \%$ na evasão escolar de cursos superiores na área de tecnologia no Brasil. A autora menciona ainda outra pesquisa realizada pela Sociedade Brasileira de Computação (SBC), a qual confirma o alto número de reprovação e conclui que não vê indícios de melhora nos índices de formação de novos profissionais na Computação nos próximos anos. Com esse cenário assustador diversos professores, pedagogos e pesquisadores vêm tentando compreender os desafios e melhorar os métodos de ensino e por consequência os índices de aprendizagem e de aprovação em disciplinas de algoritmos, resultando assim, em um melhor quantitativo e qualitativo de formandos nos cursos dessa área, a qual apresenta um dos mais promissores mercados de trabalho (TIMMERMANN, 2015; COSTA e SOUZA, 2017; SANTOS e COSTA, 2006; LIMA JUNIOR et. al, 2015). Entre as tentativas de melhorias podem-se destacar o uso de Tecnologias da 
Informação e Comunicação (TICs) e das metodologias de aprendizagem baseadas em problemas (ou projetos, ABP) no processo de ensino e aprendizagem. Ambas são metodologias que estimulam a proatividade e o aprimoramento pessoal em um grupo acadêmico por meio de discussões profundas de casos interdisciplinares.

Contudo, esse trabalho tem o objetivo de apresentar a metodologia e os resultados de um projeto denominado "PRÁTICA DE PROGRAMAÇÃO PARA MARATONA" que foi desenvolvido em um campus do Instituto Federal de Minas Gerais (IFMG) nos anos de 2018 e 2019 com o foco de motivar os alunos do curso Técnico em Informática, pois os resultados das disciplinas de programação e consequentemente o número de desistências da área da computação no campus não fogem aos números apresentados pela Brasscom e SBC.

O projeto utilizou TICs e a metodologia de aprendizagem por problemas, apresentando aos alunos questões propostas pela Olimpíada Brasileira de Informática. O resultado do projeto culminou em uma melhora do rendimento dos alunos nas disciplinas de programação, maior motivação dos envolvidos no projeto (discentes e docentes) e consequentemente, melhoras nos dados referentes à desistência dos alunos. Tais resultados apresentam indícios de que projetos desse tipo podem ser eficientes e podem ser mais uma estratégia para melhorar o ensino e a aprendizagem de algoritmos nos cursos de Computação.

O restante desse trabalho está assim distribuído: a Seção 2 faz a fundamentação teórica sobre as técnicas, conceitos e metodologias utilizadas nessa pesquisa; a terceira seção descreve a metodologia proposta e aplicada; a Seção 4 mostra os resultados alcançados e, por fim, a Seção 5 apresenta as conclusões da pesquisa.

\section{Fundamentação teórica}

A sociedade atual é altamente dependente de tecnologia, a todo o momento meios de comunicação e transporte, procedimentos médicos ou simples ações de entretenimento utilizam equipamentos eletroeletrônicos e, a maioria desses dispositivos são gerenciados por uma camada lógica chamada programa, do inglês, software. O conceito de programação, segundo Wirth (1989), é a técnica de construir e formular algoritmos de uma forma sistemática utilizando uma linguagem de programação, ou seja, 
uma linguagem que é entendida por dispositivos eletrônicos. Ela é capaz de descrever através de uma sequência de passos ordenados a realização de uma tarefa em um período de tempo finito e produzir um resultado previsível e bem definido (ASCENCIO e CAMPOS, 2003).

Para Santos e Costa (2006), programação é uma ciência que envolve um conjunto de princípios, técnicas e formalismos que visam ao desenvolvimento de produtos de softwares bem estruturados e confiáveis. Isso envolve a análise do que deve ser construído, documentação do projeto e produto final, estudo de técnicas de armazenamento, recuperação de dados e de problemas computáveis. Contudo, percebese pela vasta área de conhecimento exigido, o porquê de o estudo de algoritmos ser a estrutura central dos projetos pedagógicos, principalmente os que seguem as diretrizes curriculares proposta pelo MEC para os cursos da área de Computação, tanto no ensino médio quanto no superior (AZEREDO, 2000).

\section{Técnicas tradicionais de ensino de algoritmos}

ASCENCIO e CAMPOS (2012, p. 3) afirmam que as três técnicas mais utilizadas na criação de algoritmos na fase do aprendizado são a descrição narrativa, o fluxograma e o pseudocódigo. A Tabela 1 faz uma síntese dessas técnicas. Essas três técnicas são exemplificadas na Figura 1, a qual descreve a solução para um algoritmo simples que mostra o resultado da multiplicação de dois números.

Essas técnicas também são apresentadas em diversos livros da área (ARAÚJO, 2007; FOBERLLONE e EBERSPÄCHER, 2005; MANZANO e OLIVEIRA, 1997). Técnicas e estruturas de conteúdo criticadas pelos autores Gondin e Ambrósio (2008, p. 2), que acham essa abordagem pouco atrativa. Timmermann (2015, p. 42), enfatiza que a grande maioria da literatura segue um fluxo de capítulos semelhantes e ao final de cada capítulo é disponibilizada uma lista massiva de exercícios. Para a autora, isso pode ser perigoso, pois pode criar uma confusão entre os conceitos de exercício e problema, nesse caso, os alunos devem resolver problemas e acabam fazendo exercícios. Quando um aluno resolve um exercício pode não necessariamente estar resolvendo um problema. 0 exercício envolve mera aplicação de conteúdos ministrados, enquanto o problema necessariamente envolve invenção e/ou criação significativa (SETTI, 2009, p. 06). 
Tabela 1 - Técnicas de escrita de algoritmos durante a aprendizagem

\begin{tabular}{|c|c|c|c|}
\hline Técnica & Descrição & Vantagem & Desvantagem \\
\hline $\begin{array}{l}\text { Descrição } \\
\text { narrativa }\end{array}$ & $\begin{array}{l}\text { Utiliza uma linguagem } \\
\text { natural (exemplo, a } \\
\text { língua portuguesa), } \\
\text { para descrever os } \\
\text { passos a serem } \\
\text { seguidos para a } \\
\text { resolução do } \\
\text { problema. }\end{array}$ & $\begin{array}{l}\text { Não é necessário } \\
\text { aprender nenhum } \\
\text { conceito novo, pois } \\
\text { uma língua natural, } \\
\text { neste ponto, já é } \\
\text { bem conhecida. }\end{array}$ & $\begin{array}{l}\text { A língua natural abre } \\
\text { espaço para várias } \\
\text { interpretações, o } \\
\text { que dificulta a } \\
\text { transcrição desse } \\
\text { algoritmo para o } \\
\text { programa. }\end{array}$ \\
\hline Fluxograma & $\begin{array}{l}\text { Utiliza símbolos } \\
\text { gráficos predefinidos } \\
\text { para descrever os } \\
\text { passos a serem } \\
\text { seguidos para a } \\
\text { resolução do } \\
\text { problema. }\end{array}$ & $\begin{array}{l}\text { O entendimento de } \\
\text { elementos gráficos } \\
\text { é mais simples que } \\
\text { o entendimento de } \\
\text { textos. }\end{array}$ & $\begin{array}{l}\text { É necessário } \\
\text { aprender a } \\
\text { simbologia dos } \\
\text { fluxogramas com } \\
\text { uma transcrição para } \\
\text { o algoritmo não } \\
\text { natural. }\end{array}$ \\
\hline Pseudocódigo & $\begin{array}{l}\text { Descreve, por meio de } \\
\text { regras predefinidas, os } \\
\text { passos a serem } \\
\text { seguidos para sua } \\
\text { resolução. }\end{array}$ & $\begin{array}{l}\text { A passagem do } \\
\text { algoritmo para } \\
\text { qualquer linguagem } \\
\text { de programação é } \\
\text { quase imediata. }\end{array}$ & $\begin{array}{l}\text { É necessário } \\
\text { aprender as regras } \\
\text { do pseudocódigo. }\end{array}$ \\
\hline
\end{tabular}

Fonte: Adaptado de ASCENCIO e CAMPOS (2012).

Figura 1 - Exemplo das técnicas de abstração de algoritmos na aprendizagem 


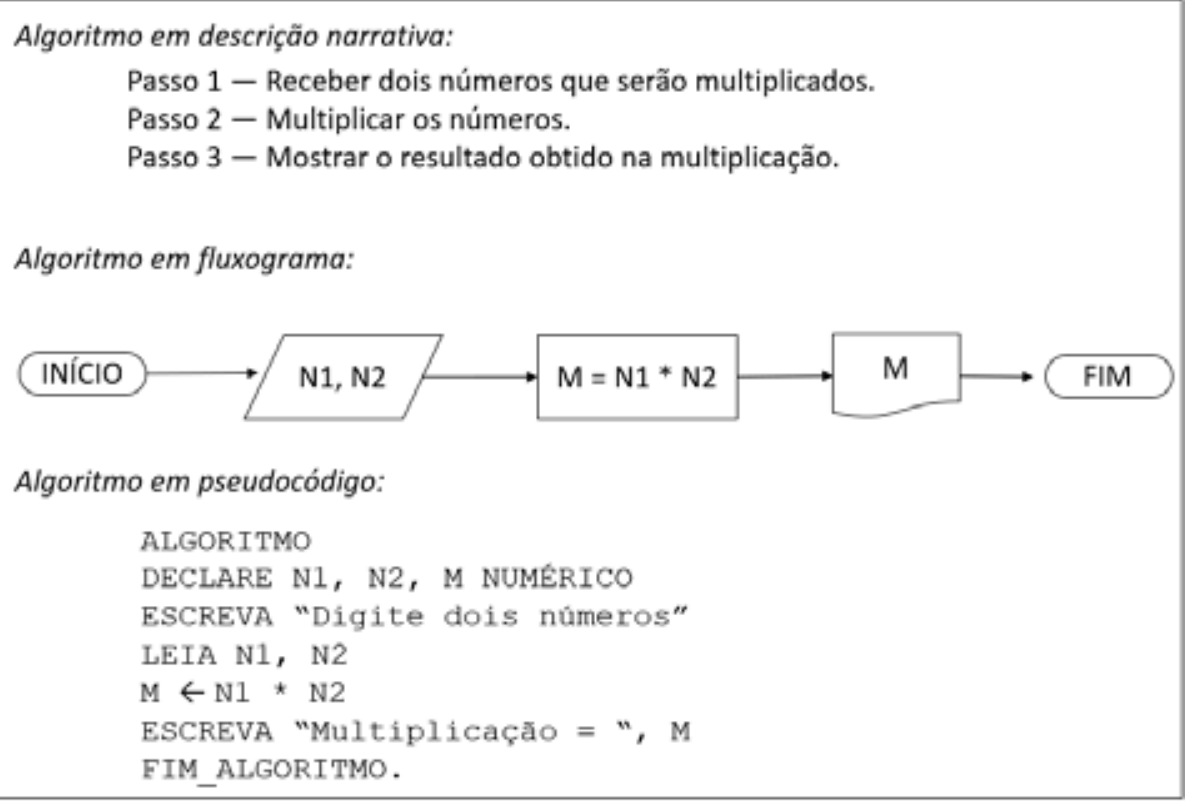

Fonte: Adaptado de ASCENCIO e CAMPOS (2012).

\section{O ensino de algoritmos por meio de Tecnologia da Informação e Comunicação (TICs)}

Há algumas poucas décadas, a sociedade passou a viver uma série de transformações com a popularização dos computadores pessoais e com o uso de tecnologias da informação e comunicação (TICs), as quais podem ser compreendidas como todas as tecnologias que fazem parte dos processos informacionais e comunicativos da sociedade (KENSKI, 2012, p.46). De forma análoga, essas mudanças vêm sendo sentidas também na educação, principalmente pelo uso de tais dispositivos. Um dos primeiros relatos de uso de tecnologia no ensino foi o do professor Sidney Pressy, no ano de 1924, o qual inventou uma máquina de corrigir provas de múltipla escola. A partir desse marco diversas propostas para o desenvolvimento de objetos de aprendizagem como softwares educacionais e afins vêm sendo empregados na educação (VIEIRA JUNIOR, 2018 p. 2).

Valente (2011) apresenta diversos estilos de ferramentas que podem ser utilizadas como TICs para implementar um objeto de aprendizagem, como por exemplo, jogos educacionais, simuladores, comunicadores instantâneos e softwares para a resolução de problemas. Ênfase deve ser dada a esse último, o qual é caracterizado pelo próprio autor como uma ferramenta responsável por propiciar um ambiente de aprendizado baseado na resolução de problemas. Esse tipo de ferramenta adiciona novas dimensões ao ensino, 
principalmente ao ensino e aprendizagem de algoritmos. Esses softwares aceitam diversas linguagens de programação e como a solução proposta pelo usuário pode ser verificada através da sua execução, a pessoa que o utiliza pode verificar suas ideias e conceitos. Se existe algo errado, ele pode analisar o programa e identificar a origem do erro.

Existem diversas opções de ferramentas para a correção de algoritmos. Hemming e Franzen (2018) apresentam várias delas, com destaque para a plataforma da Code Shool $^{1}$. Ela oferece a possibilidade para o aluno testar o código diretamente no navegador Web, outra característica é a utilização da experiência de gamificação ${ }^{2}$ no aprendizado, encorajando o aluno a continuar. As outras ferramentas são a Khan Academy $^{3}$ e a Code Chef ${ }^{4}$. A primeira dessas duas disponibiliza exercícios, vídeos e um sistema de aprendizado personalizado que habilita os estudantes a aprender no seu próprio ritmo, com a abordagem de assuntos como: busca binária, ordenação, algoritmos recursivos e grafos. O Code Chef é uma plataforma de competição de desafios em programação, atualmente com suporte a mais de 50 linguagens, contando com uma grande comunidade de estudantes e profissionais.

Na mesma linha existe o Neps Academy, o qual disponibiliza cursos que vão desde a introdução à programação até conceitos de Inteligência Artificial. O portal eletrônico apresenta também uma ferramenta de correção de exercícios em tempo real, com o objetivo de treinar os alunos para competições na área da Computação (NEPS ACADEMY, 2020).

O Run Codes é um sistema gratuito de submissão e correção automática de exercícios de programação. Ele tem suporte a diversas linguagens como Java, $C / C_{++}, R$, entre outras. Segundo o site da própria ferramenta, os exercícios são corrigidos em segundos e o aluno pode verificar a nota e detalhes sobre a correção. Ao mesmo tempo, o professor pode acompanhar o desempenho e a evolução de seus alunos por meio de dados estatísticos, além de contar com o recurso de verificação de similaridade (RUN CODES, 2020).

\footnotetext{
${ }^{1}$ https://hsmuniversity.com.br/code-school/ Acessado em 01/05/2020.

${ }^{2}$ https://mundoekoa.com/2020/04/14/gamificacao-na-educacao-tantos-beneficios-nao-podem-fazer-mal/ Acessado em 25/06/2020.

${ }^{3}$ https://pt.khanacademy.org/ Acessado em 01/05/2020.

${ }^{4}$ https://www.codechef.com/ Acessado em 01/05/2020.
} 
O Boca é um ambiente que foi concebido para ser um sistema de apoio a competições de programação para a Maratona de Programação da Sociedade Brasileira de Computação (DE CAMPOS e FERREIRA, 2004). A plataforma possui um recurso conhecido como juiz online, o qual realiza a avaliação automática dos algoritmos submetidos. Segundo os autores, o sistema pode ser usado também no apoio a disciplinas em que se faça uso de submissão e correção de trabalhos durante as aulas (ASCENCIO e CAMPOS, 2003).

É importante ressaltar que um tipo de software fundamental ao ensino de algoritmos é o ambiente integrado de desenvolvimento (ou do inglês, Integrated Development Environment - IDE). Esse tipo de software tem os elementos necessários para o processo de desenvolvimento de algoritmos, como o compilador (responsável por converter o algoritmo em código executável de máquina), ferramentas de conexão a bancos de dados, instalação da aplicação em um servidor, ferramentas de depuração e refatoração, entre outros. Resumindo, a IDE deve ter a capacidade de proporcionar a solução para problemas usuais de desenvolvedores/alunos.

\section{Técnicas de ensino com o uso da metodologia de aprendizagem por problemas (ABP)}

Constitui como natureza humana fugir ou ter medo de situações que tendem a lidar com problemas. Mas o dia a dia é cercado de tais ações e as pessoas devem deliberar sobre dificuldades a serem transpostas, as quais estão inseridas no âmbito social, escolar ou profissional. Isso fez surgir quase de forma natural a metodologia de Aprendizagem Baseada em Problemas, ou simplesmente conhecida como ABP (ou até mesmo PBL, sigla oriunda do inglês, Problem Based Learning). Essa metodologia tenta mesclar teoria e prática. O objetivo é que a aprendizagem seja mais dinâmica e que o estudante seja inserido à teoria e possa testá-la ao mesmo tempo. Assim, os alunos tendem a se tornarem mais engajados (NOEMI, 2019).

O professor não é o único ator ativo no processo de aprendizagem, ele apenas guia os estudantes até o conhecimento. São apresentados problemas cotidianos e, a partir deles, os conceitos são aplicados. Por exemplo, nas disciplinas ligadas a algoritmos, 
pode ser apresentado o problema de encontrar o caminho mais curto entre dois pontos da cidade e nesse contexto introduzir o conceito de Grafos ${ }^{5}$.

Uma das formas para aplicar o ABP, a fim de fortalecer a necessidade de uma perspectiva de ensino mais voltada para a construção do conhecimento pelo aluno, é através do Arco de Maguerez (BORDENAVE e PEREIRA, 1989). A Figura 2 mostra a ideia central por trás da metodologia. Assim, o problema se dá a partir de um determinado aspecto da realidade. Então, a primeira etapa é a da observação da realidade e definição do problema. Os alunos, apoiados pelo professor, selecionam uma das situações e a problematizam. Depois dessa discussão inicial os envolvidos definem os pontos chaves do estudo, cuja investigação possibilitará uma nova reflexão sobre o mesmo. A terceira etapa - a da teorização - é o momento de construir respostas mais elaboradas para o problema. Os dados obtidos, registrados e tratados, são analisados e discutidos, buscando-se um sentido para eles. Na etapa de hipóteses de solução a criatividade e a originalidade devem ser bastante estimuladas para se pensar nas alternativas de solução do problema. Já a última etapa possibilita o intervir, o exercitar, o manejar de situações associadas à solução do problema (COLOMBO, 2007).

Figura 2 - Arco de Maguerez aplicado ao ABP

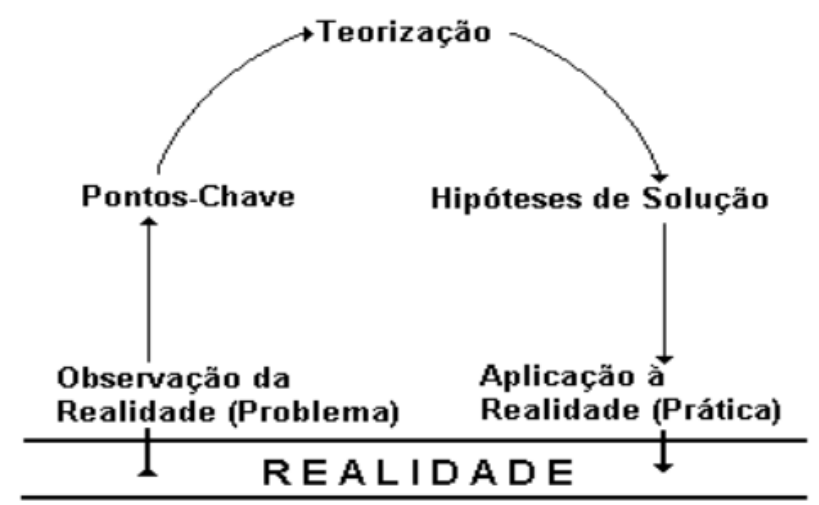

Fonte: BORDENAVE e PEREIRA (1989).

${ }^{5}$ https://www.inf.ufsc.br/grafos/definicoes/definicao.html. Acessado em 11/06/2020 
A Sociedade Brasileira de Computação (SBC), sabendo do potencial do Aprendizado Baseado em Problemas, vem organizando desde 1999 a Olimpíada Brasileira de Informática (OBI). O objetivo, segundo o site do evento ${ }^{6}$, é despertar nos alunos o interesse por ciência da computação através de atividades que envolvem desafios, engenhosidade e uma saudável dose de competição. Para praticar, os estudantes podem submeter soluções para problemas das provas da OBI de anos anteriores e verificar se as soluções estão corretas. Estão disponíveis tarefas para diferentes níveis de dificuldade. Na modalidade de iniciação as provas são sobre problemas de lógica, na modalidade de programação são exigidas soluções algorítmicas e possui três níveis de dificuldade (nível 1, nível2 e nível sênior).

\section{Trabalhos relacionados ao ensino de algoritmo com métodos inovadores}

O aprendizado baseado em problemas, o uso de TICs na educação e mesmo a junção dos dois conceitos em sala de aula, não são uma novidade. Existem diversos experimentos e relatos de uso dessas técnicas em várias áreas do conhecimento. Por exemplo, Fujita et al. (2016) usou ABP no ensino sobre brinquedos terapêuticos na graduação de enfermagem, o que resultou na criação de dez brinquedos terapêuticos. Lopes et al. (2011) relata o uso bem sucedido da aprendizagem baseada em problemas na disciplina de Química no Ensino Médio, o qual abordou o uso de pesticidas e seus efeitos na saúde humana. O processo de ensino foi baseado em um caso real de intoxicação e terminou com uma apresentação dos relatórios de atividades dos alunos.

$\mathrm{Na}$ área da Computação e com o foco no ensino em algoritmos pode ser apresentado o trabalho de Delgado et al. (2004), que apresenta a experiência com ABP, ou seja, através do uso de uma metodologia baseada na atuação do professor como facilitador, no papel proativo do aluno e em recursos didáticos voltados para o desenvolvimento da capacidade de abstração, do raciocínio lógico, da solução de problemas e da autonomia cognitiva. Os autores obtiveram como resultado o maior engajamento dos alunos durante as aulas e consequentemente no número de aprovações. Sousa (2011) segue na mesma linha e apresenta bons resultados ao aplicar

\footnotetext{
${ }^{6}$ Site oficial da OBI: https://olimpiada.ic.unicamp.br/. Acessado em 04/05/2020.
} 
ABP como estratégia de ensino e aprendizagem em uma disciplina de Introdução à Computação no primeiro ano de um curso de licenciatura em Química.

Referente ao uso de TICs, Dazzi e Miranda (2000), Mendes e Gomes (2000) e Medeiros e Dazzi (2002) propõem ferramentas próprias para automatizar a correção e dar mais dinamismo ao ensino de algoritmos. Santos e Costa (2005), apresentam uma ferramenta com uma abordagem um pouco diferente, os autores propõem um software educacional de simulação gráfica que representa passo a passo as instruções do algoritmo com o objetivo de complementar o material teórico acerca da manipulação das estruturas de dados tradicionais. Cristovão (2008), apresenta a experiência com a utilização do ambiente de programação Scratch, ambiente de programação voltado para crianças a partir de 8 anos de idade criado pelo MIT Media $L a b^{7}$, o qual permitiu, segundo o autor, a adoção de uma aprendizagem significativa e por consequência trouxe motivação para os alunos.

Gerhardt et al. (2018) relatam o uso de ferramentas automatizadas de correção de algoritmos e o uso de metodologias baseada na resolução de problemas para motivar os alunos, melhorar a didática e a eficiência no ensino de programação para os alunos do nível fundamental da rede pública da Grande Vitória, no Espírito Santo.

Contudo, observa-se que os trabalhos: Dazzi e Miranda (2000), Mendes e Gomes (2000) e Medeiros e Dazzi (2002), apresentam relatos de usos de TICs no ensino, mas não mencionam metodologias de aplicação ou não são voltadas à $A B P$, já os trabalhos de Delgado et al. (2004) e Sousa (2011) apresentam metodologias baseadas em problemas, mas não relatam o uso de ferramentas computacionais para auxiliar no ensino de algoritmos. Gerhardt et al. (2018), apresentam os resultados do uso da junção dessas duas técnicas para um projeto de extensão envolvendo escolas públicas do ensino médio na Grande Vitória, o que se assemelha ao apresentado nesse trabalho, porém será apresentado aqui um relato de experiências de um projeto de ensino aplicado aos estudantes do ensino Técnico Integrado em Informática do IFMG.

\section{Metodologia}

\footnotetext{
${ }^{7}$ https://www.media.mit.edu/ Acessado em 04/05/2020.
} 
Um dos campi do Instituto Federal de Minas Gerais implantou recentemente (2018) o curso Técnico em Informática. Esse curso tem uma entrada anual de oitenta estudantes que são separados em duas turmas com números iguais de participantes (Turmas A e B). O curso tem o foco principal no desenvolvimento de sistemas computadorizados, dando consequentemente um grande enfoque às disciplinas de programação. Assim, a disciplina de Introdução à Programação do primeiro ano é base para o restante do curso. Esse requisito, em conjunto com o cenário econômico e sociocultural da região aonde se encontra o campus, na qual tem um enfoque agropecuário $^{8}$, fez surgir a necessidade de motivar os alunos do então recém-criado curso técnico.

Depois de um estudo da literatura, o qual foi apresentado na Seção 2 desse texto (pág. 4), concluiu-se que somente os métodos de ensino tradicionais não seriam suficientes. Assim, optou-se por empregar a metodologia de ABP em conjunto com TICs no ensino de algoritmos. Contudo, foi criado o projeto “PRÁTICA DE PROGRAMAÇÃO PARA MARATONA" e colocado em prática nos anos letivos de 2018 e 2019.

O primeiro passo do projeto foi escolher os softwares que seriam utilizados. Essas escolhas foram feitas seguindo os princípios indicados por Vieira Junior (2018, p.12), o qual afirma que a aplicação da tecnologia educacional também requer um estudo pedagógico para que a intervenção seja, verdadeiramente, educacional. Contudo, ele sugere planejamento para: (1) a escolha do objeto de aprendizagem; e para (2) a definição de metodologia de uso.

Contudo, o Netbeans foi o software escolhido para ser a IDE de desenvolvimento de algoritmos. Esse é um programa de computador que os alunos utilizariam de forma individual para criar e executar os algoritmos nas máquinas dos laboratórios. Ele é um dos ambientes de desenvolvimento gratuito mais utilizados pelos desenvolvedores da linguagem Java. Possui assistentes, que facilitam o processo de configuração e também geram código, dando o suporte necessário para que os usuários se preocupem mais com a lógica do algoritmo e menos com implementações e processos secundários ${ }^{9}$. O restante dos softwares utilizados já foram apresentados na Seção 2 (pág. 7). A ferramenta Neps Academy foi utilizada para a correção automática de algoritmos e para facilitar a busca de

\footnotetext{
${ }^{8}$ https://www.cidade-brasil.com.br/municipio-sao-joao-evangelista.html. Acessado em 07/05/2020.

${ }^{9}$ https://www.devmedia.com.br/explorando-o-netbeans-7-0-artigo-java-magazine-91/21121
} 
conhecimento, pois ela possui material de apoio para a resolução dos problemas (tutoriais, vídeo aulas, entre outros), além disso, esse software disponibiliza uma base de problemas prontos para serem explorados. O Run Codes também foi utilizado. Ele também faz a correção automática dos algoritmos, mas tem a grande vantagem de ter uma base de problemas editável, assim o professor pode inserir problemas regionais e foi por esse motivo que essa ferramenta foi inserida nesse projeto. Por último, o Boca, foi utilizado para realizar as competições internas, de cunho educativo, do projeto e do campus.

Com essas ferramentas, o projeto buscou aprimorar os fundamentos da programação de computadores. O objetivo foi explorar conteúdos conceituais, procedimentais e atitudinais através da metodologia ABP. A metodologia visa criar momentos particulares e comunicativos, isso, de acordo com as atividades em aula, e as ferramentas de softwares escolhidas proporcionam momentos para trabalho individual e em grupo.

Para guiar a criação do projeto utilizaram-se também os conceitos metodológicos propostos por Zabala (1998, p. 19), a qual se preocupa com quatro eixos de ação (Sintaxe, Ação social, Princípios de reação e Sistema de apoio). As descrições desses eixos no projeto são apresentadas nas quatro subseções seguintes.

\section{Sintaxe}

No eixo nomeado como Sintaxe, os autores do projeto devem listar o conjunto de atividades sequenciadas. Assim, as ações anuais envolveram três fases macros. A primeira envolveu a divulgação, uma vez que o projeto foi aprovado pela comissão do campus, foi iniciado o processo de divulgação. Durante este período, o projeto foi apresentado aos alunos do primeiro ano do curso técnico em informática e foi solicitada aos mesmos a manifestação de interesse em participar por meio de assinatura de uma lista, incluindo o nome e o e-mail de contato de cada um.

Na segunda etapa, ou etapa de execução, os alunos cadastrados no projeto, foi definido juntamente com os participantes um horário na semana que não prejudicasse as aulas de outras disciplinas. Os encontros aconteceram uma vez por semana durante uma hora e trinta minutos no laboratório de informática da escola. 
A terceira etapa é a de avaliações. Como critério de avaliação deste projeto foi analisado o desempenho dos estudantes na disciplina de Introdução à Programação, e, além disso, foi verificado o desempenho dos mesmos em competições ao longo do ano letivo.

\section{Sistema social}

$\mathrm{Na}$ fase conhecida como Sistema social, deve-se descrever os papéis dos envolvidos e as relações e tipos de normas que prevalecem. No projeto foi definido a existência de dois atores básicos, o professor e o aluno e suas ações são definidas no Quadro 1:

Quadro 1 - Listagem das funções de cada ator do projeto

Papel do professor:

- A presentar a didática e as ferramentas do projeto;

- Apresentar os conceitos teóricos de forma expositiva;

- Mostrar de forma prática como aplicar o conhecimento de forma algorítmica;

- Apresentar problemas práticos e gerenciar a discussão do tema;

- Instigar os alunos a descobrir, buscar e propor soluções;

- Confrontar e confirmar os resultados dos alunos.

\section{Papel do estudante:}

- Explorar o ambiente de aprendizagem para reforçar os conceitos e fazer novas descobertas;

- Executar as tarefas das atividades em sala de aula;

- Buscar de forma proativa o conhecimento necessário para resolver os problemas propostos;

- Discutir com os envolvidos a vantagens e desvantagens das soluções propostas;

- Validar e verificar os conceitos aprendidos.

Fonte: Elaboração própria.

\section{Princípios de reação.}

Nesse eixo, as regras de interação com o aluno e quais são os objetivos a essas interações são definidos, nesse caso, o guia foram as etapas do Arco de Maguerez aplicado à ABP (Seção 2, pág. 10). Durante cada encontro aconteciam cinco etapas básicas. No início, observação da realidade, os alunos eram apresentados ao 
tema/problema a ser trabalhado no dia. Assim, discussão sobre o tema, com promoção da integração entre os estudantes e construção coletiva do problema a ser tratado eram realizadas. Em seguida, pontos chave eram levantados. Esse momento promovia a reflexão e a discussão coletiva sobre as questões levantadas pelos alunos na etapa anterior. O objetivo é trabalhar a criticidade e a elaboração de uma síntese do estudante.

A terceira etapa, conhecida como Teorização, incentivava o estudante a buscar informações sobre o problema de cada ponto chave, aqui o aluno poderia usar a Internet, biblioteca ou matérias disponibilizadas pelas próprias ferramentas como: o material fornecido pelo Neps Academy. O objetivo é reforçar o protagonismo na busca de informações, contando com momentos individuais e coletivos de construção do conhecimento.

Na etapa seguinte, chamada de Hipóteses de solução, eram elaboradas soluções para o problema, isso subsidiado pelas informações levantadas nas etapas anteriores. Aqui o objetivo era criar o algoritmo para a solução do problema. Isso variava entre pseudocódigos, fluxogramas ou mesmo o algoritmo executável no Netbeans. Na última etapa, Aplicação à realidade, os algoritmos eram criados e/ou testados utilizando as ferramentas de apoio à aprendizagem, nesse ponto, e o Run Codes e/ou Neps Academy eram empregados. Além disso, uma apresentação dos resultados era feita. Outra atividade dessa fase era a participação dos estudantes nas competições internas e na OBI.

\section{Sistema de apoio}

Nesse eixo, devem-se descrever as condições necessárias, tanto físicas como pessoais, para que exista uma boa intervenção. Foi definido que o participante deve estar cursando ou ter cursado alguma disciplina de introdução aos conceitos de algoritmos. Em conjunto, foram definidos os equipamentos necessários durante o período do projeto:

- Laboratório de Informática e espaço para trabalho em grupo;

- Computadores individuais com acesso à Internet e com todos os programas instalados;

- Para a parte expositiva, foram necessários datashow, quadro branco e pincel e

- O material de apoio como: livros, tutoriais, vídeo aulas, entre outros. 


\section{Detalhes da execução do projeto}

O projeto foi anual e ocorreu em 2018 e 2019, com duração de dois trimestres, isso porque o calendário da instituição era dividido em três etapas. O primeiro trimestre era usado para divulgação e seleção dos alunos. Esse tempo inicial foi interessante também para os estudantes adquirirem os conceitos iniciais da disciplina a serem exercitados no início do projeto.

No primeiro ano (2018), o experimento foi frequentando por 20 estudantes (7 da turma A e 13 da turma B). No segundo ano (2019) o projeto contou com 12 selecionados (7 da turma A e 5 da turma B). Todos esses discentes eram matriculados no primeiro ano do curso Técnico em Informática, os quais se inscreveram de forma voluntária depois de divulgação no campus. Os encontros nos dois anos aconteceram em complemento às aulas da disciplina de Introdução à Programação. Assim, os estudantes se reuniram no laboratório de informática da escola todas as quartas-feiras durante uma hora e trinta minutos (14:45 às 16:15). Esse horário era oportuno porque não existem aulas regulares de nenhum curso no campus nesse dia e horário da semana. Praticamente todas as atividades eram realizadas nesse período para não sobrecarregar os estudantes, contudo, desafios inacabados e soluções consideradas insatisfatórias eram retrabalhadas em casa pelos alunos de forma espontânea.

Os conceitos em relação aos algoritmos, como por exemplo, sintaxe da linguagem e estrutura de dados, eram apresentados durante a disciplina regular do curso técnico. Assim, a ordem do conteúdo exigido para resolver os problemas práticos no projeto seguiram essa mesma ordem cronológica da ementa da disciplina. No laboratório, as regras para as ações em sala com os alunos foram regidas pelo Arco de Maguerez aplicado à ABP (Seção 2, pág. 10) e mencionadas na Seção 3 (pág. 15). Como os alunos utilizavam o Run Codes ou Neps Academy para implementar os problemas, os resultados eram exibidos em instantes e as ideias para resolver os problemas eram validadas ou refutadas sem a necessidade constante de interação com o professor.

No primeiro ano de execução do projeto os integrantes participaram da olimpíada interna de programação da escola, no segundo ano, os integrantes do projeto também fizeram parte dessa competição saudável e alguns alunos do projeto foram selecionados para representar o campus na Olimpíada Brasileira de Informática (OBI). 


\section{Resultados}

Para essa pesquisa foram realizados três tipos de análises com o objetivo de verificar se os resultados da iniciativa proposta foram positivos. A ideia nesse ponto foi observar se o uso de TICs e da ABP no ensino de algoritmos melhorou o rendimento acadêmico e atitudinal dos inscritos no projeto na disciplina de Introdução à Programação. Assim, a primeira e segunda análises foram quantitativas, ou seja, sobre a colocação dos estudantes nas competições de programação e sobre as notas finais dos mesmos no primeiro ano do curso. Já na terceira análise, foi realiza uma consulta qualitativa através de um questionário eletrônico para compreender a percepção dos participantes do projeto perante os assuntos referentes à programação de computadores.

\section{Analise nas competições}

No ano de 2018 os participantes do projeto se inscreveram pela primeira vez na maratona interna de programação do campus, que contou com a participação de alunos de todos os anos letivos. Cada equipe era formada por três estudantes. Na etapa final do evento, seis entre os 9 alunos eram participantes do projeto, sendo que uma das equipes obteve medalha de ouro e outra equipe medalha de bronze. No ano de 2019 o sucesso na participação da competição interna se repetiu e o grande destaque foi a classificação dos estudantes do projeto como membros da primeira equipe do campus IFMG na Olimpíada Brasileira de Informática.

Os estudantes participantes deste projeto concorreram na modalidade de programação nível 1 da OBI, destinada a alunos de todo o país que estiverem cursando até o primeiro ano do ensino médio. No ano 2019, o nível 1 contou com a participação de 3295 competidores em todo o país. A Tabela 2 apresenta a classificação dos sete melhores estudantes participantes do projeto de ensino naquele ano (5 não se classificaram para a segunda etapa e não tiveram os resultados divulgados). A partir destes dados é possível identificar que os estudantes conseguiram ficar entre os $12 \%$ melhores estudantes de programação do primeiro ano do ensino médio no Brasil. 
Tabela 2 - Classificação nacional dos estudantes na OBI 2019

\begin{tabular}{lll}
\hline Participante & $\begin{array}{l}\text { Colocação Nacional } \\
\text { (Entre 3295) }\end{array}$ & $\begin{array}{l}\text { Porcentagem (\%) } \\
\text { (Melhores } \\
\text { estudantes) }\end{array}$ \\
\hline Estudante 1 & $216^{\circ}$ & 6,6 \\
\hline Estudante 2 & $237^{\circ}$ & 7,2 \\
\hline Estudante 3 & $297^{\circ}$ & 9,0 \\
\hline Estudante 4 & $297^{\circ}$ & 9,0 \\
\hline Estudante 5 & $359^{\circ}$ & 10,9 \\
\hline Estudante 6 & $361^{\circ}$ & 11,0 \\
\hline Estudante 7 & $365^{\circ}$ & 11,1 \\
\hline \hline
\end{tabular}

Fonte: Elaboração própria.

Como mostra a Tabela 2, um dos participantes do projeto se destacou na competição obtendo a classificação de número 216 entre 3295 estudantes de todo o país. Um resultado expressivo e motivador não só para os próprios estudantes do projeto, mas para todos os estudantes de todo o campus.

\section{Análise acadêmica}

Outro indicativo importante a ser destacado está relacionado ao desempenho dos estudantes da disciplina de Introdução à Programação. A seguir serão apresentados os dados das notas dos estudantes antes e após o início do projeto. O “antes” contempla o primeiro trimestre, quando foram distribuídos 30 pontos e é o período em que os alunos ainda não estavam participando do projeto. O "depois" se refere ao período de participação do projeto, o qual contempla dois trimestres, sendo distribuídos 35 pontos em cada um destes períodos. Assim, as notas apresentadas a seguir foram normalizadas numa escala de zero a cem. 
As Figuras 3 e 4 apresentam as notas, respectivamente, das turmas A (7 estudantes) e B (13 estudantes) dos ingressantes em 2018. Em ambas as turmas o percentual de estudantes que melhoraram seus rendimentos (65\%) é consideravelmente maior que o percentual daqueles que mantiveram a mesma performance (10\%) e que aqueles que obtiveram rendimento menor (25\%). Os números são um indicativo de que o projeto contribuiu para melhorar o desempenho dos participantes.

Figura 3 - Comparativo de Notas dos Estudantes da Turma A / 2018, desempenho dos participantes Antes $\times$ Depois

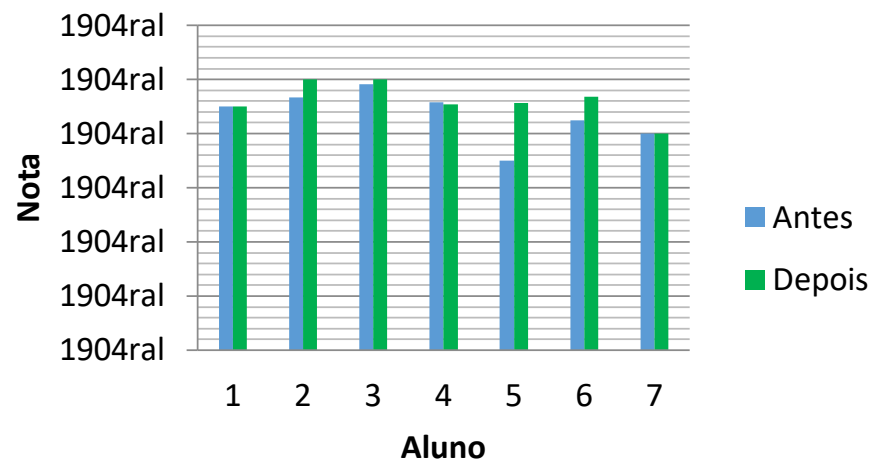

Fonte: Elaboração própria.

Figura 4 - Comparativo de Notas dos Estudantes da Turma B / 2018, desempenho dos participantes Antes $\times$ Depois

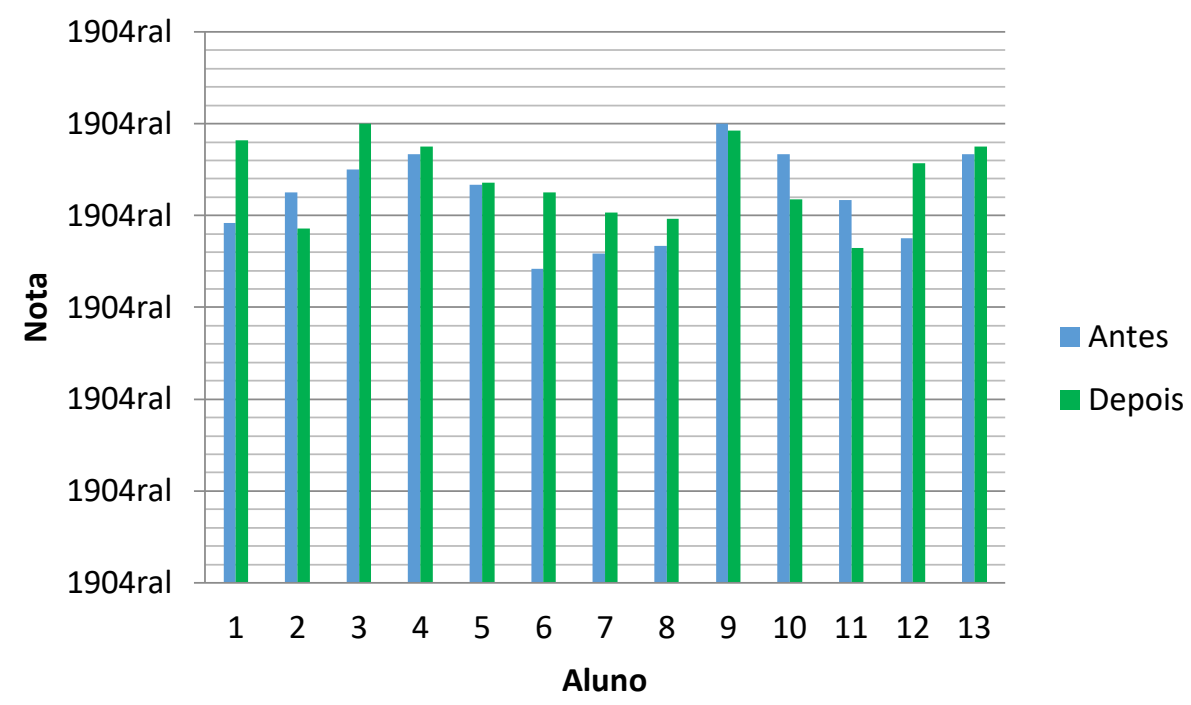

Fonte: Elaboração própria. 
Na Figura 5 é possível identificar que na turma A de 2019, após o início do projeto de ensino houve uma melhora no desempenho de 71\% dos estudantes. Também é possível identificar que $100 \%$ dos estudantes desta turma foram capazes de obter um aproveitamento na disciplina de Introdução à Programação acima de $90 \%$.

Figura 5 - Comparativo de Notas dos Estudantes da Turma A de 2019, participantes Antes $\times$ Depois.

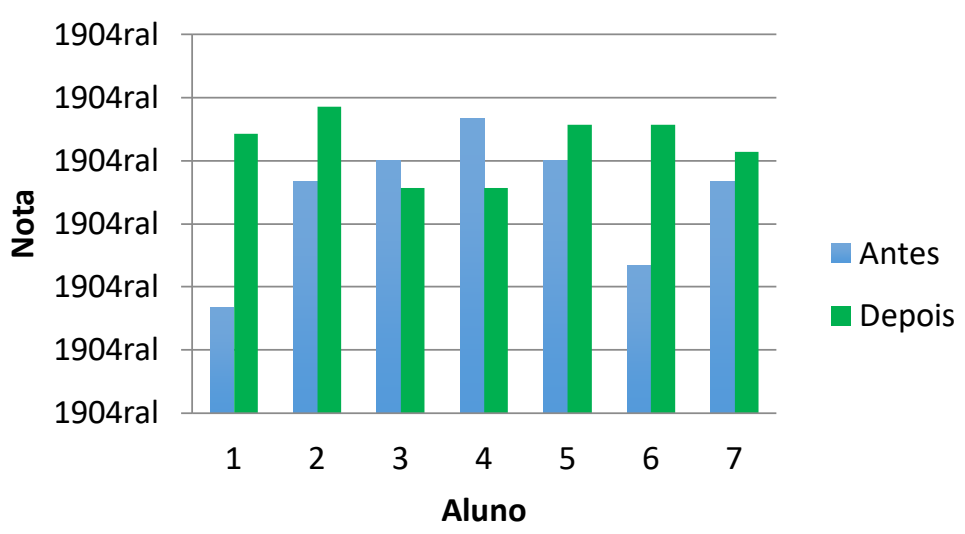

Fonte: Elaboração própria.

A Figura 6 mostra os dados das notas dos estudantes da turma B de 2019, aonde é possível identificar que a maioria dos estudantes obtiveram notas acima de $80 \%$ após o projeto de ensino, e apesar da matéria ir dificultado ao longo do ano, apenas dois alunos não mantiveram ou melhoraram a nota (Aluno 2 teve uma ligeira queda).

Figura 6 - Comparativo de Notas dos Estudantes da Turma B de 2019, participantes Antes $\times$ Depois.

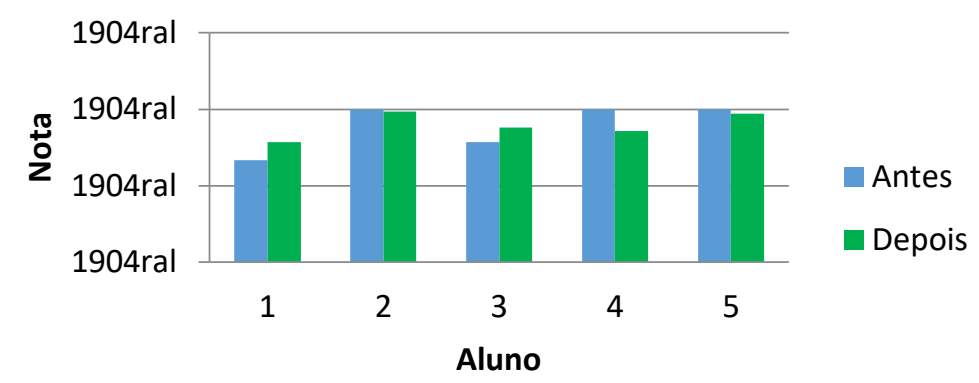

Fonte: Elaboração própria. 
A Figura 7 apresenta a média das notas de todos os estudantes participantes e não participantes nos três trimestres dos anos letivos de 2018 e 2019 na disciplina de Introdução à Programação. Em um total de 143 estudantes, 32 participaram do projeto de ensino, 20 em 2018 e 12 em 2019. Pela Figura 7 observa-se que os estudantes que não participaram do projeto permaneceram com sua nota média nos três trimestres abaixo de $80 \%$ enquanto que os participantes do projeto obtiveram notas próximas de $90 \%$. Este é mais um indicativo da eficiência do projeto com relação ao aprendizado de temas referentes a algoritmos.

Figura 7- Comparativo de notas dos estudantes participantes × não participantes de 2018 e 2019.

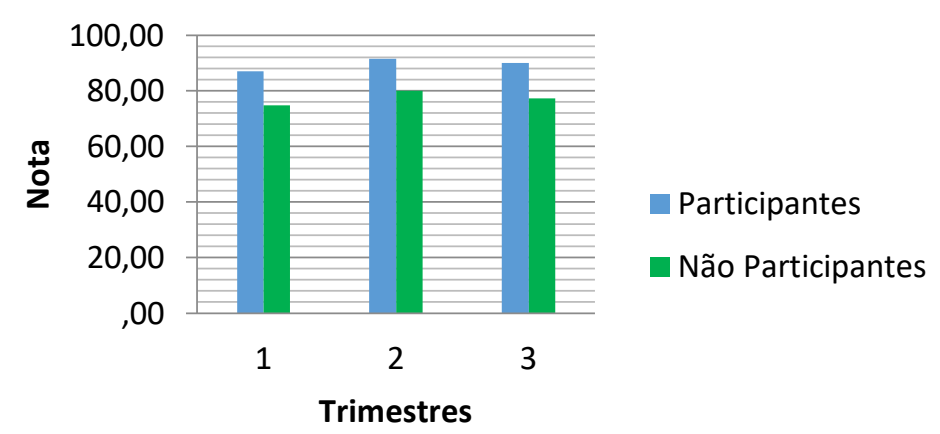

Fonte: Elaboração própria.

A Figura 8 apresenta um gráfico de dispersão de notas dos estudantes antes e depois do projeto, no eixo horizontal é representada a nota antes, enquanto que o eixo vertical apresenta a nota após o projeto.

Em uma análise geral é possível identificar que nos dois anos (2018 e 2019), o projeto de ensino contribuiu para que a maioria dos participantes obtivesse uma melhora em suas notas na disciplina de Introdução à Programação, visto que a maioria das notas representadas no gráfico está acima da diagonal principal.

Figura 8- Distribuição de notas dos estudantes antes e depois do projeto 


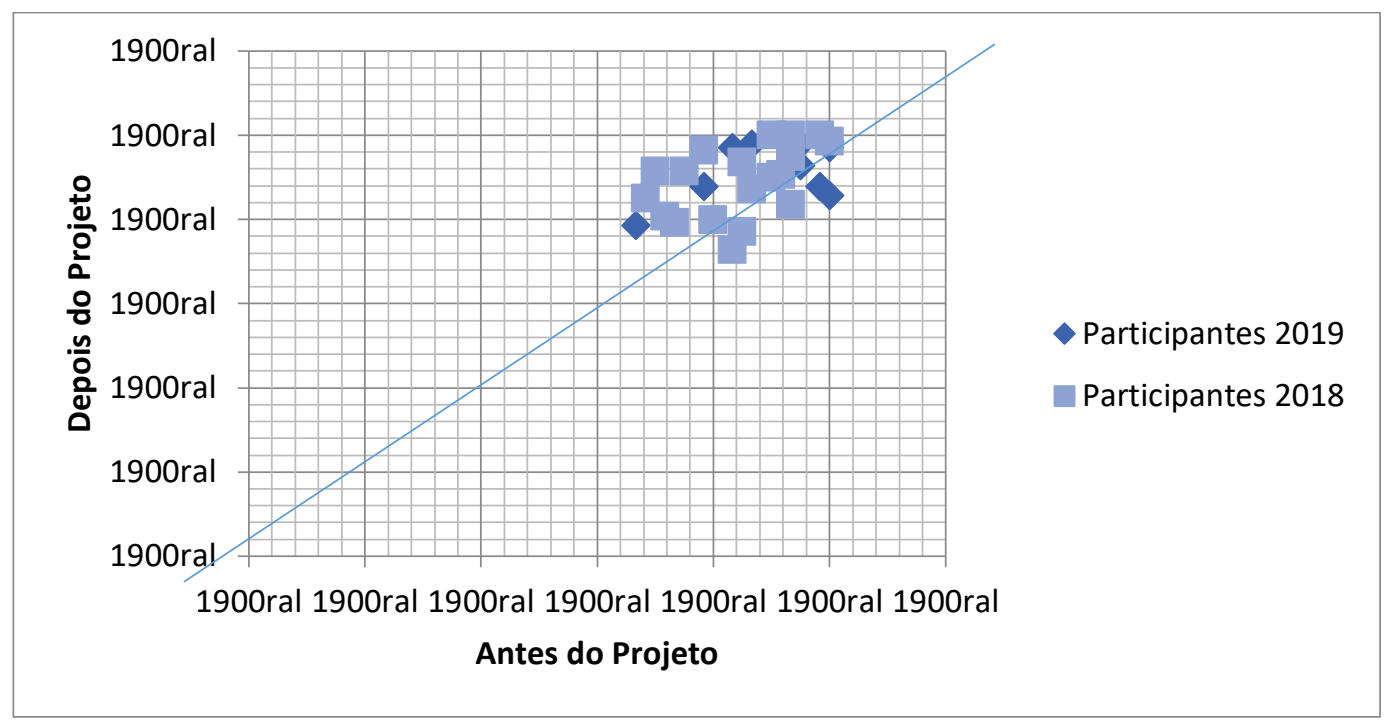

Fonte: Elaboração própria.

Ao analisar friamente a média final das notas dos estudantes de 2018 e 2019 apresentadas na Figura 7, percebe-se que o aproveitamento dos participantes do projeto é de $90 \%$, enquanto que os outros estudantes tiveram um aproveitamento médio de $78 \%$. Porém, cabe ressaltar nesse momento, que os autores entendem que o desempenho escolar é diferente da aprendizagem (COATA JUNIOR, 2017; FERRÃO, 2003), sabe-se também que fatores como o nível socioeconômico, a idade e o sexo também influenciam a proficiência dos estudantes (SCOPEL, 2012). Contudo, para os propósitos específicos desse trabalho, o desempenho representado pelas notas dos estudantes é usado como mais um indício relevante do sucesso do projeto, pois mostra que a nota do estudante participante é apenas uma consequência de seu empenho no projeto, uma vez que ele foi estimulado durante o ano a desenvolver seu raciocínio lógico para resolver problemas com os mais variados níveis de dificuldade.

\section{Análise de percepção dos participantes}

Para reforçar a eficácia da metodologia aplicada nessa pesquisa revelada quantitativamente, os 32 participantes, referente às duas edições do projeto, foram convidados a responderem de forma espontânea e anônima uma pesquisa de percepção. A ideia foi analisar o projeto do ponto de vista dos estudantes. Assim, foi enviado um email contendo um questionário eletrônico com assertivas de múltiplas escolhas baseadas 
na escala proposta por Likert (1932). Nesta escala são dispostas afirmações e cada afirmação deve ser avaliada em uma escala de concordância ou discordância (VIEIRA E DALMORO, 2008; JÚNIOR E COSTA, 2014). Além dessas questões, duas perguntas abertas/descritivas davam a oportunidade aos participantes para indicarem respectivamente os pontos positivos e o que poderia ser melhorado no projeto, na visão deles. Essas duas últimas perguntas não eram de preenchimento obrigatório. As assertivas do questionário são apresentadas nas legendas das Figuras 9 a 13.

Os resultados a seguir apresentam as respostas de 13 estudantes que se dispuseram a ajudar nessa aferição dos resultados. A participação de aproximadamente $40 \%$ dos estudantes na pesquisa talvez fosse maior se ela tivesse ocorrido logo ao final de cada ano do projeto, mas ela foi realizada somente no início do ano de 2020, contudo os autores acreditam que esse percentual ainda é representativo.

Na Figura 9, o gráfico apresenta que 53,8\% dos estudantes concordam totalmente e $23,1 \%$ concordam parcialmente que o projeto foi importante na aquisição de novos conhecimentos sobre programação de computadores. Dessa forma, além do que foi revelado pelos resultados quantitativos, aproximadamente $77 \%$ dos respondentes reconhecem a eficiência da metodologia do projeto para a obtenção de conhecimentos sobre programação.

Figura 9 - "Eu adquiri conhecimentos sobre programação participando do projeto".

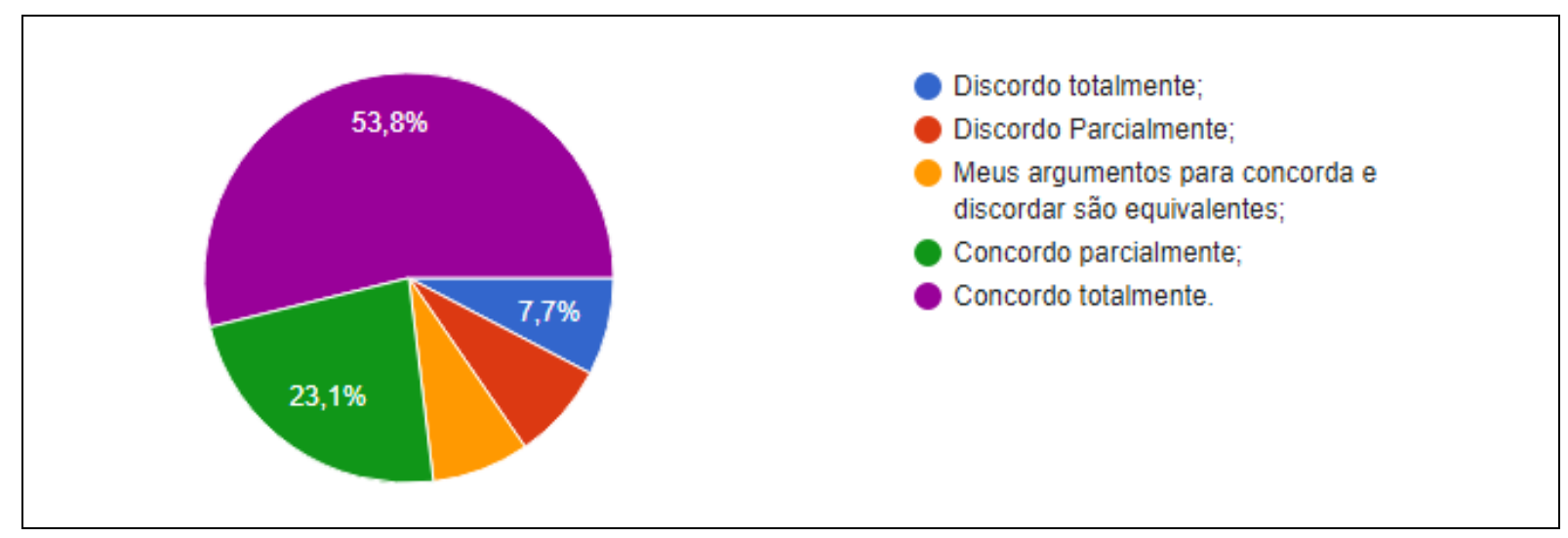

Fonte: Elaboração própria.

A Figura 10 apresenta a percepção dos respondentes quanto à sua melhoria no desempenho na disciplina de Introdução à Programação. Neste caso, novamente $77 \%$ dos 
entrevistados concordam totalmente ou parcialmente que o projeto auxiliou no desempenho acadêmico deles, corroborando os resultados quantitativos.

Figura 10 - "Eu melhorei meu desempenho na disciplina de Introdução a programação".

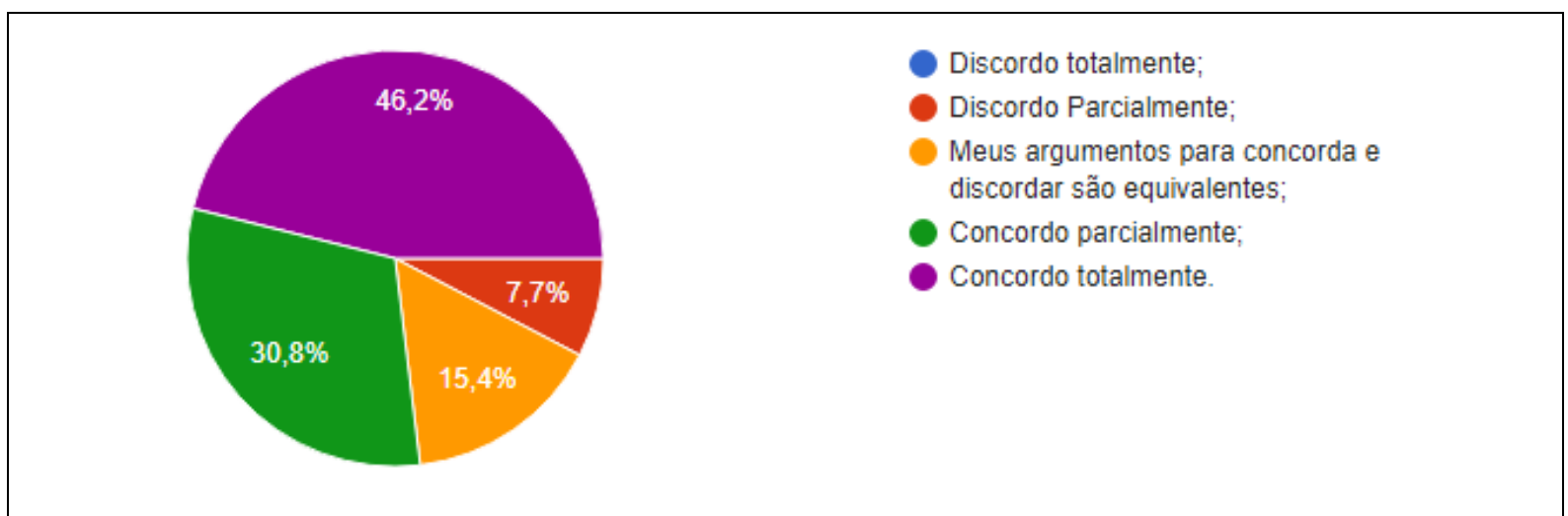

Fonte: Elaboração própria.

Observando a Figura 11 é possível identificar que o projeto de ensino foi muito relevante em auxiliar o desenvolvimento do raciocínio lógico na construção de algoritmos para $69,3 \%$ dos respondentes. Conhecimento que é fundamental para a autossuficiência dos profissionais da área para resolver problemas e desenvolver softwares que realmente atendam às necessidades dos clientes. Um aluno confiante nesse quesito é confiante para procurar emprego e atuar na área. Além disso, o raciocínio lógico é essencial para a disciplina de Introdução à Programação, mostrando que a percepção dos discentes dialoga com os resultados quantitativos sobre a disciplina.

Figura 11 - "O projeto me ajudou a desenvolver o raciocínio lógico na construção de algoritmos".

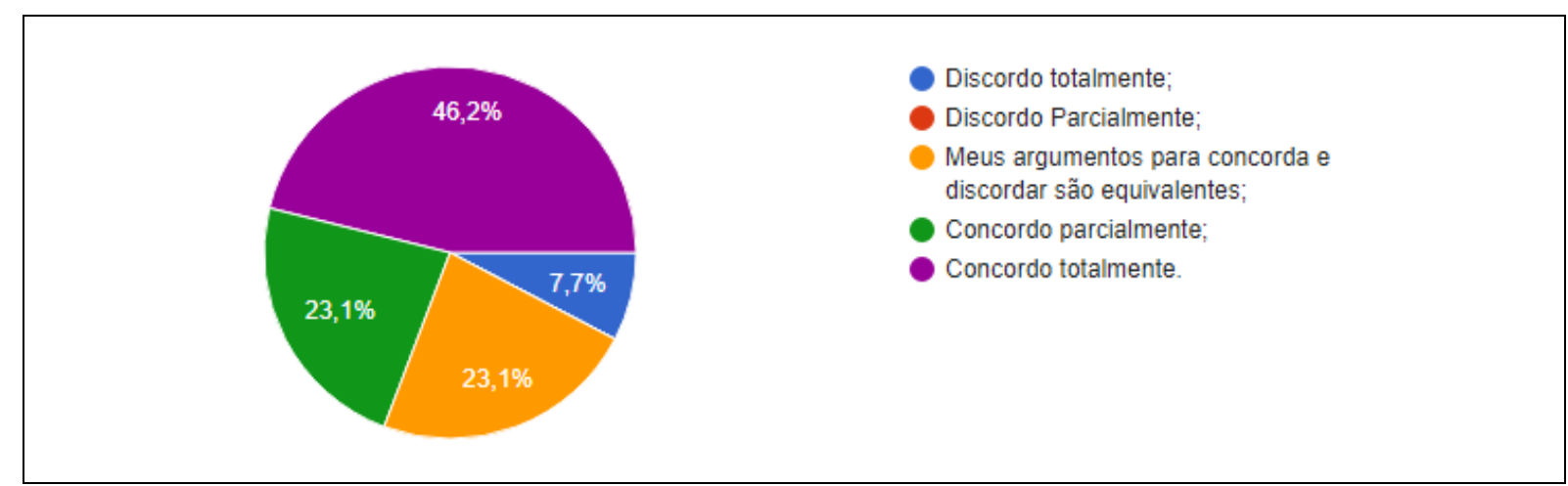

Fonte: Elaboração própria. 
A Figura 12 destaca a importância do uso das tecnologias de Informação no auxílio do processo de ensino e aprendizagem. Tais ferramentas foram muito úteis na detecção e apontamento dos erros nos algoritmos e também na verificação das saídas esperadas para cada problema estudado. O uso das TICs foi bem avaliado por $76,9 \%$ dos respondentes.

Figura 12 - "As Tecnologias de Informação me ajudaram no aprendizado durante o

$$
\text { projeto". }
$$

$\begin{array}{ll}53,8 \% & \text { Discordo totalmente; } \\ & \text { Discordo Parcialmente; } \\ & \text { Meus argumentos para concorda e } \\ \text { discordar são equivalentes; } \\ \text { Concordo parcialmente; } \\ 23,1 \% \quad \text { Concordo totalmente. }\end{array}$

Fonte: Elaboração própria.

Outra percepção relevante apresentada está relacionada à recomendação deste projeto. A Figura 13 mostra que $92,3 \%$ dos respondentes concordam parcialmente ou totalmente em recomendar o projeto de ensino a um amigo, o que revela a percepção de benefícios e ganhos acadêmicos por parte dos discentes.

Figura 13 - "Eu recomendaria um amigo a participar do projeto".

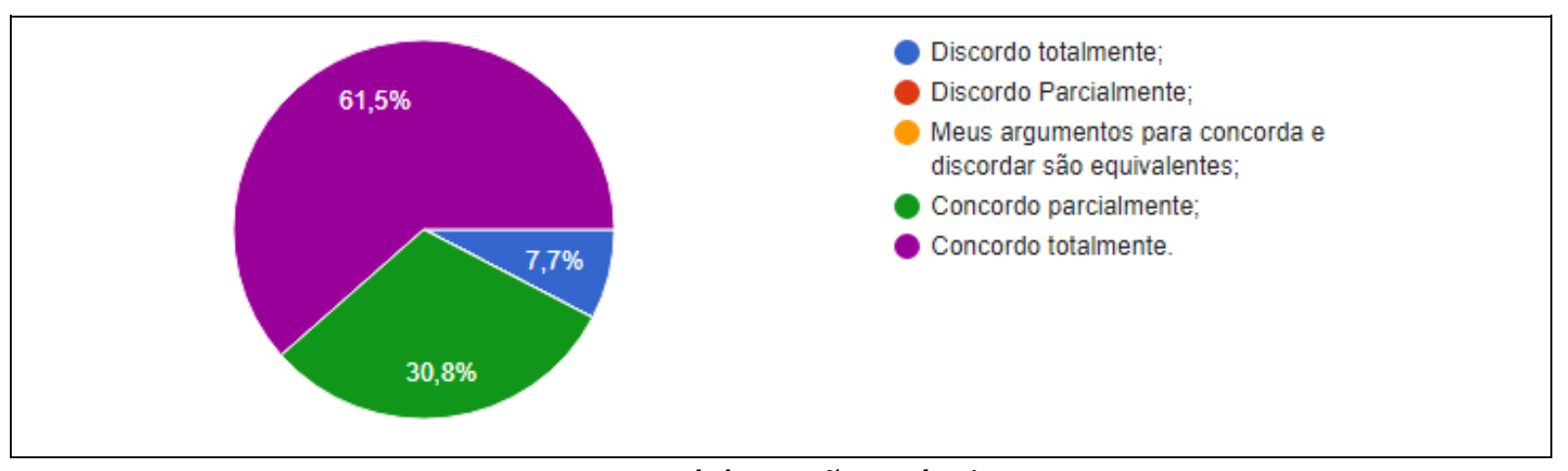

Fonte: Elaboração própria.

Referente às perguntas descritivas do questionário, a primeira dizia "Por favor, nos conte o que você gostou no projeto de ensino" e foi preenchida por cinco pessoas 
com respostas curtas. As quais foram: 1) A didática; 2) Através do projeto foi possível ampliar os conhecimentos adquiridos nas aulas de programação; 3) Participação e apoio ativos de um profissional da área; 4) O que eu mais gostei foi a dinâmica de apresentar problemas para resolver e aprimorar o método de concepção de ideias e planejamentos dos algoritmos e 5) Gostei do auxilio que os professores deram ajudando muito na disciplina. Já a última pergunta, "Por favor, nos conte o que você não gostou no projeto.", teve apenas uma resposta curta que dizia a palavra "Nada”.

\section{CONSIDERAÇÕES FINAIS}

O mercado de trabalho vem demandando uma grande quantidade de profissionais que atuem nos mais variados ramos e etapas do desenvolvimento de softwares, contudo, existe uma carência de tais profissionais. Um dos motivos desse cenário não é a falta de escolas ou treinamento nessa área, mas sim a dificuldade e o desinteresse dos postulantes a este campo de trabalho quando se deparam com a necessidade de dominar os conceitos acerca de algoritmos.

O alto índice de reprovações e desistências nas disciplinas acadêmicas ligadas a linguagens de programação são notórias e vem sendo estudado por diversos autores, os quais apontam os métodos atuais de ensino como um dos fatores determinantes. Frente a isso, esse trabalho propôs uma abordagem que emprega TICs e a metodologia de Aprendizagem Baseada em Problemas para ajudar a transpor as barreiras do ensinoaprendizagem encontradas pelos alunos de cursos técnicos e do ensino superior. $O$ objetivo foi utilizar uma metodologia ABP através de um projeto para promover a criatividade e a proatividade dos alunos na aprendizagem de conceitos fundamentais de algoritmos.

Ao final de dois anos letivos de aplicação do projeto, a metodologia proposta vem demonstrando fortes indícios de que vem cumprindo o objetivo. Os alunos participantes do projeto foram capazes de manter a concentração, disciplina, responsabilidade e persistência no aprendizado da lógica de programação. Além disso, a maioria dos estudantes se tornaram autossuficientes na busca e na obtenção de conhecimentos. Eles desenvolveram habilidades para investigar e resolver problemas concretos, o que comprova isso é a pesquisa de percepção de aprendizagem dos alunos participantes do 
projeto, o índice de aprovação dos mesmos nas disciplinas regulares do curso Técnico em Informática e os bons resultados dos mesmos nas competições internas do campus e na OBI.

Como uma ação de constante melhoria desse projeto que visa motivar e melhorar o ensino e aprendizagem de algoritmos pode-se citar, a sistematização de consultas da percepção do aluno sobre os benefícios do projeto, o armazenamento dos dados das questões resolvidas para identificar os assuntos em que os estudantes demonstraram mais dificuldade afim de explorar e sanar as deficiências ainda encontradas.

Com base na eficiência revelada pelos resultados quantitativos e qualitativos com relação ao uso de TICs e da ABP no ensino de algoritmos, os autores recomendam fortemente que docentes de diferentes instituições e modalidades de ensino considerem a aplicação das metodologias em disciplinas de programação.

\section{REFERÊNCIAS}

ARAÚJO, Everton C. de. Algoritmos: fundamentos e práticas. 3 ed. Florianópolis: VisualBooks, 2007.

ASCENCIO, Ana Fernanda Gomes; CAMPOS, Edilene Aparecida Veneruchi de. Fundamentos da programação de computadores. $2^{a}$ edição. São Paulo: Editora Pearson Prentice Hall, 2003.

ASCENCIO Ana F.G., CAMPOS Edilene A.. Fundamentos da programação de computadores: algoritmos, pascal, C/C++. 3a ed . São Paulo: Editora Pearson, 2012.

AZEREDO, P. A. Uma proposta de plano pedagógico para a matéria de programação. Anais do II curso: qualidade de cursos de graduação da área de computação e informática (WEI 2000). Editora Universitária Champagnat, 2000.

BARCELOS, Ricardo; TAROUCO, Liane; BERCHT, Magda. O uso de mobile learning no ensino de algoritmos. RENOTE - Revista Novas Tecnologias na Educação, v. 7, n. 3, dez.2009, p. 327-337.

BORDENAVE, J. D.; PEREIRA, A. M. Estratégias de ensino aprendizagem. 4. ed. Petrópolis: Vozes, 1989.

COLOMBO A. A., A. Metodologia da problematização com o arco de maguerez e sua relação com os saberes de professores. Semina: Ciências Sociais e Humanas, Londrina, v. 28, n. 2, jul./dez. 2007, p. 121-146. 
CORMEN, Thomas H.; LEISERSON, Charles E.; RIVEST, Ronald L.; STEIN, Clifford. Algoritmos: teoria e prática 1. Tradução da segunda edição [americana] Vandenberg D. de Souza. Rio de Janeiro: Elsevier, 2002.

COSTA JUNIOR, Edio da et al. Um estudo estatístico sobre o aproveitamento em física de alunos de ensino médio e seus desempenhos em outras disciplinas. Rev. Bras. Ensino Fís., São Paulo, v. 39, n. 1, 2017.

COSTA, Mayara Capucho; SOUZA, Maria Aparecida Silva de. O uso das TICs no processo ensino e aprendizagem na escola alternativa "Lago dos Cisnes". Revista Valore, v. 2, n. 2, nov. 2017. p. 220-235.

CRISTOVÃO, H. M.. "Aprendizagem de algoritmos num contexto significativo e motivador: um relato de experiência". In: Anais do XXVII Congresso da Sociedade Brasileira de Computação. Belém do Pará: PA, 2008.

DAZZI, R. L. S.; MIRANDA, E. M.; SOUZA, E. M. S. SAEL: Sistema de apoio ao ensino de lógica de programação. In: Workshop de informática aplicada à educação, Araraquara, 2000.

DE CAMPOS, C. P.; FERREIRA, C. E.. Boca: um sistema de apoio a competições de programação (BOCA: A Support System for Programming Contests). In: Workshop de educação em bomputação (Brazilian Workshop on Education in Computing), 2004, Salvador: Anais do Congresso da SBC, 2004.

DELGADO, C., XEXEO, J. A. M., SOUZA, I. F., CAMPOS, M., RAPKIEWICZ, C. E. "Uma abordagem pedagógica para a iniciação ao estudo de algoritmos". Salvador/BA: XII Workshop de Educação em Computação (WEl'2004), 2004

FERRÃO, M. E. e FERNANDES, C. O efeito-escola e a mudança - dá para mudar? Evidências da investigação brasileira. REICE. Revista Iberoamericana sobre Calidad, Eficacia y Cambio em Educación, v. 1, n. 1, 2003, p. 1-13.

FILHO, Cléuzio F. História da computação: o caminho do pensamento e da tecnologia. Porto Alegre: EDIPUCRS, 2007.

FOBERLLONE, A. L. V. EBERSPÄCHER, H. F. Lógica de programação: a construção de algoritmos e estruturas de dados. 3. Ed. São Paulo: Pearson Prentice Hall, 2005.

FUJITA, J. A. L. M., CARMONA, E.V., SHIMO A.K.K.S., MECENA, E. H. Uso da metodologia da problematização com o Arco de Maguerez no ensino sobre brinquedo terapêutico. Revista Portuguesa de Educação, Braga, v. 29, n. 1, jun. 2016. p. 229-258.

GERHARDT, L. O., I.. BUSTAMANTE, M. R.. MAI, L. F. F.. NUNES , N. R.. SANDRINI, L.. REZENDE, G. C.. ALOCHIO, G. S.. GOMES, R. L.. Estudo de ferramentas de apoio à correção de atividades de programação no contexto do projeto IntroComp. Anais do $V$ Senid - Seminário Nacional de Inclusão Digital - Cultura Digital na Educação, 2018 
HEMMING C., FRANZEN E. Ferramenta de apoio ao ensino e aprendizagem de algoritmos e programação. Monografia de Conclusão de Curso apresentado ao Centro de Ciências Exatas e Tecnológicas da Universidade do Vale do Taquari-UNIVATES, 2018

JÚNIOR, S. D. S.; COSTA, F. J.. Mensuração e escalas de verificação: uma análise comparativa das escalas de Likert e Phrase Completion. PMKT-Revista Brasileira de Pesquisas de Marketing, Opinião e Mídia, v. 15, p. 1-16, out. 2014.

KENSKI, V. M. Educação e tecnologias: o novo ritmo da informação. $8^{\mathrm{a}}$ ed. Campinas: Papirus, 2012.

LIKERT, Rensis. A technique for the measurement of attitudes. Archives of psychology, New York: Columbia University Press, 1932.

LIMA JUNIOR, J. A. T.; VIEIRA, C. E. C.; VIEIRA, P. de Paula. Dificuldades no processo de aprendizagem de algoritmos: uma análise dos resultados na disciplina de AL1 do curso de sistemas de informação da FAETERJ - Campus Paracambi. Cadernos UniFOA, Volta Redonda, v. 10, n. 27, p. 5-15, abr. 2015.

LOPES, Renato Matos et al. Aprendizagem baseada em problemas: uma experiência no ensino de química toxicológica. Química Nova, São Paulo, v. 34, n. 7, 2011 , p. 1275-1280.

MANZANO, J. A. N. G.; OLIVEIRA, J. G. de. Estudo dirigido de algoritmos. São Paulo: Editora Érica (Coleção PD). 1997.

MEDEIROS, C.L.; DAZZI, R.L.S. Aprendendo algoritmos com auxílio da web. Itajaí: II Congresso Brasileiro de Computação, vol. 2, 2002.

MENDES, A. J. N.; GOMES, A. J. Suporte a aprendizagem de programação com o ambiente SICAS. In: Congresso Ibero Americano De Informática Educativa-Ribie, 5., 2000, Viña del Mar-Chile. Anais... Viña del Mar-Chile: Universidad de Chile, 2000.

NEPS ACADEMY. Homepage da ferramenta. Disponível em: https://neps.academy/login?next=\%2F. Acesso em: 02 de maio de 2020.

NOEMI, D., Entenda o que é a aprendizagem baseada em problemas. Disponível em: https://escolasdisruptivas.com.br/metodologias-inovadoras/entenda-o-queea aprendizagem-baseada-em-problemas/. Acesso em: 03 de maio de 2020.

RUN CODES. Homepage da ferramenta. Disponível em: https://run.codes/. Acesso em: 02 de maio de 2020.

SANTOS, R. P. e COSTA, H. A. X. Desenvolvimento de um software educacional para o ensino de algoritmos, estruturas de dados e programação. CD de Resumos XVIII Cicesal XII Seminário PIBIC/Cnpq - VIII Seminário PBIICT/Fapemig - I Congresso de Extensão, Lavras/MG, v. 1, p. 113-113, 2005. 
SANTOS, Rodrigo P. dos S.; COSTA, Heitor A. X. Análise de metodologias e ambientes de ensino para algoritmos, estruturas de dados e programação aos iniciantes em computação e informática. INFOCOMP Journal of Computer Science, v. 5, n. 1, 2006, p.4150.

SETTI, M. de O. G. O processo de discretização do raciocínio matemático na tradução para o raciocínio computacional: um estudo de caso no ensino/aprendizagem de algoritmos. Curitiba/PR: Universidade Federal do Paraná, 2009.

SCOPEL, Ramilla Recla; SOUZA, Valquíria Conceição and LEMOS, Stela Maris Aguiar. A influência do ambiente familiar e escolar na aquisição e no desenvolvimento da linguagem: revisão de literatura. Rev. CEFAC, vol.14, n.4, 2012, p.732-741.

SOUSA, S. D. O. Aprendizagem baseada em problemas (PBL - Problem-Based Learning): estratégia para o ensino e aprendizagem de algoritmos e conteúdos computacionais. Nuances: Estudos sobre Educação, Unesp, v.18, n.19, 2011.

SOUZA, João Nunes de. Lógica para ciência da computação: uma introdução concisa. 2 ed. Rio de Janeiro: Elsevier, 2008.

TIMMERMANN, Glaucia Luciana Keidann. 0 desafio de aprender e ensinar algoritmos: mediações que professores e alunos estabelecem com o conteúdo no ensino superior. Dissertação (mestrado) - Universidade Regional do Noroeste do Estado do Rio Grande do Sul, 2015.

VALENTE, José Armando. Diferentes usos do computador na educação. Educação Pública, 2011.2 Disponível em: http://www.educacaopublica.rj.gov.br/biblioteca/tecnologia/0022.html. Acesso em: 30 abr. 2020.

VIEIRA JUNIOR, N., Tecnologias e comunicação na educação. IFMG: Apostila da Pósgraduação em Docência, 2018.

VIEIRA, K. M.; DALMORO, M.;. Dilemas na construção de escalas tipo Likert: o número de itens e a disposição influenciam nos resultados?. Rio de Janeiro: XXXII Encontro Associação Nacional de Pós-Graduação e Pesquisa em Administração, 2008.

ZABALA, A. A prática educativa: como ensinar. Porto Alegre: Artmed. 1998.

WIRTH, N. Algoritmos e estruturas de dados. LTC Informática-Programação, 1989.

Recebido em: 14/07/2020

Parecer em: 30/10/2020

Aprovado em: 15/02/2021 